\title{
29 CHALLENGES FOR CREATIVITY AND INNOVATION IN MOBILE AND TRANSIENT VIRTUAL ENVIRONMENTS
}

\author{
Carl Adams \\ University of Portsmouth \\ Portsmouth, UK
}

\begin{abstract}
This position paper examines the processes of creativity and innovation within the current context of virtual working. There is a discrepancy between innovation practice and support techniques: techniques are dominated by group activity, yet much of the work on instances of creativity indicate individual activity. There are considerable challenges in supporting creativity and innovation in virtual groups, however it is an area calling for innovation and the paper proposes where this innovation may take place.
\end{abstract}

Keywords Creativity and innovation, mobile and transient e-collaboration, diffusion of innovation

\section{INNOVATION AND TECHNOLOGICAL PROGRESS}

Innovation has fueled the development and progress in technology, business, and social activity and played an important role throughout the development of mankind (Gabor 1970). One current set of innovations has resulted in the virtual world, which is redefining business and working practices, organizations, markets, trade, and social interaction (Gibson 2003). The virtual organization is typically dynamic and flexible involving transient groups of people coming together for specific tasks (Cascio 1999, p. 7). Information systems development and support are sectors actively engaged in virtual working: Teams often consist of international group members, consisting of a mix of

Please use the following format when citing this chapter.

Adams, C., 2007, in IFIP International Federation for Information Processing, Volume 235, Organizational Dynamics of Technology-Based Innovation: Diversifying the Research Agenda, eds. McMaster, T., Wastell, D., Ferneley, E., and DeGross, J. (Boston: Springer), pp. 445-451. 
outsourced and offshored elements and transient work workforces (Aalder 2001). However, the virtual organization, like any other, is based on collaboration and it is within this virtual environment that creativity and innovation will have to develop. Achieving creativity and innovation within virtual environments will face extra challenges in fostering and maintaining collaboration among dispersed and transient groups of people, often with their own goals and objectives.

\section{INNOVATION AND CREATIVITY}

Innovations are not just technology. For instance, Gabor (1970) includes 137 inventions and innovations in his book, 73 of them classed as hardware, 27 as biological, and 37 as social. A good example of social innovations is the development of the PERT planning system that evolved when developing the Polaris submarine and so enabled coordination on large-scale projects. Gibson (2003) gives further examples. Innovations and inventions take place when someone identifies a set of problems that need addressing or notices a potential opportunity to do something different. Roberts (1989) describes 36 fairly major discoveries that had considerable pseudo-serendipity in the discovery process, the accidental discovery activity when the inventor is looking for something, though possibly not the thing they eventually found. This concept has similarities with Pasteur's "prepared mind." Roberts' examples are predominantly of individual innovative and creative activity. Many of the examples given rely on an environment enabling a free flow of ideas to develop and so enabling insight. This free flow of ideas supports work by de Bono $(1969,1977)$.

There seem to be distinct elements in the creative problem solving process. First the identification of the need or problem to be addressed, which itself may involve, even require, some creativity. The mind has to be well prepared with sufficient knowledge of the problem domain. The next stage seems to involve a free flow of ideas where different alternatives are considered. The examples found in the literature indicate that these moments of innovation are predominantly individual activities. This is supported by the high proportion of individual patents filed (Huebner 2005). Harrison's (2006) Book of Inventions, also provides insightful snapshots of the activity behind many inventions and their inventors: inventions usually have single inventors, although several inventors often examine the same problem, creating competitive forces to driving innovation. The group activity in the main seems to involve the later stages, that of comparing alternatives and choosing. Of course, there will be examples where moments of innovations and creativity arise out of group activity, but the majority of the examples recalling such moments are individual events.

\section{LITERATURE ON INNOVATION AND CREATIVE SUPPORT}

The literature on support for innovation and creativity covers a range of different techniques. Jantsch (1967) examined over 100 techniques for general business and technological forecasting; the Royal Society's work on risk assessment (Royal Society 1992) provided numerous techniques from several business areas; Bicheno's (1994) descrip- 
tions of 50 techniques and business tools; Obolensky's (1994) studies of a range of business reengineering techniques; and nearly 100 further techniques from de Bono (1969, 1977), Adams (1987), Couger (1995), and Adams and Avison (2003) to improve creativity, innovation, and general problem solving in a variety of domains from general business to information systems development. There are, of course, similarities between many of these techniques, and many are effectively a re-badging of earlier techniques. However, the majority of these are based around group activity involving collaboration between team members. There seems to be a tension here between the practice, involving individual creative moments, and the group interaction norms suggested in the techniques. To understand these tensions, we will have to examine what the innovation and creativity support techniques do. Adams and Avison, while examining a range of techniques used in information system development, identify some of the attributes and advantages that techniques bring:

The use of a technique may offer one or more of the following advantages:

- Reduces the solution of a problem to a manageable set of tasks.

- Provides guidance on addressing the problem situation.

- Adds structure and order to tasks.

- Provides focus and direction to tasks.

- Provides cognitive tools to address, describe and represent the problem situation.

- Provides the basis for further analysis or work.

- Provides a communication medium between interested parties.

- Provides an output of the problem solving activity

- Provides support to the practitioner (Adams and Avison 2003, p. 205).

Techniques support goes beyond the creativity and innovation activity and includes providing support for people to work together and developing common problem definitions and acceptance, or buy-in, of the problems and any solutions. This is very similar to the concept of the collective mind and mindful interaction that Weick and Roberts (1993) identify as essential for efficient and reliant teams.

However, there seems to be a tension between individual and group creativity, especially with the personal creativity tasks (Gladstein 1984). Bharadwaj and Menon (2000, p. 424) examine individual and organizational creativity mechanisms and identify a range of tensions. Clearly the tensions between individual and groups creativity are complex and involved. These tensions are resolved in some part by the designed tasks within the support techniques, and also through the embedded structures within the organization. In the pre-virtual world, this mostly meant face-to-face interaction within organizations where clear official structures and business protocols evolved to support business activity. At the same time, corresponding informal structures and protocols also evolved alongside the formal (Hutchison and Rosenberg 1994, p. 7; Adams 2005). This is a theme taken up by Bloomfield (1992), who argues for a "socially adequate view of organizations" (p. 204).

The informal and formal aspects are both important for effective collaboration (Adams 2005). However, fully functional teams take time to develop and work out responsibilities and protocols (Stewart 1991). It seems clear that the more transient teams are, then the bigger challenges they will have in achieving cohesion, shared goals, and 
a collective mind set. Weick and Roberts identify the need for rich communication structures between individuals within working groups. In addition, the type of interaction with newcomers into the group is also an indicator of the level of collective mind: "The quality of collective mind is heavily dependent on the way insiders interact with newcomers" (Weick and Roberts 1993, p. 368). A developed collective mind provides key elements of common problem framing and integrating new members into the common mind set.

Many authors on using creativity/innovation techniques recommend some consideration of the make-up of different groups (e.g., Bicheno 1994; Couger et al. 1993), although they give limited practical guidance on doing so. It seems that support techniques are performing a complex set of roles, not least getting common mind sets, mindful interaction, and buy-in of problems and solutions. Addressing the limitations of the virtual environment in achieving group cohesion as well as utilizing the capabilities of the environment to foster creativity and innovation is an area calling for innovation.

\section{CONCLUSION AND WAY FORWARD}

This paper has explored the processes of creativity and innovation within the current context of virtual working. The paper identified a discrepancy between works on innovation practice and the works covering support for innovation: Work on innovation and creative problem solving techniques is dominated by group activity, yet many actual instances of innovation and creativity indicate a predominance of individual activity. This tension between individual practice and group support is typically resolved in traditional face-to-face environments by the embedded social and formal structures. However, more challenges occur within the current climate of virtual working environments where social and formal structures are less strong. The virtual context also involves more transience and mobility of group members. Achieving buy-in for common problems, and any creative innovations to address those, are more difficult.

There seems to be an opportunity for creative and innovative solutions to emerge which address limitations of the virtual environment in achieving group cohesion. The traditional creativity and innovation support techniques need to be adapted to foster virtual interaction, and collaboration. Use of rich media, frequent interaction and informal interaction are areas that clearly offer potential for developing and supporting trust within development groups and achieving common mind sets, mindful interaction, and buy-in of problems and solution. Possibly the biggest impact will be by social innovations, developing new interaction activity and norms for virtual and reliant groups. There also seems to be an opportunity for utilizing the capabilities of the virtual environment to foster creativity and innovation at the individual level. After all, that is where omst creative moments take place. There is clearly a need for more research into the complex creative problem-solving activity with the trend toward virtual working and involving dispersed and often mobile transient groups.

\section{References}

Aalder, R. The Outsourcing Guide, New York: Wiley, NY, 2001. 
Adams, C. "Supporting Structures for Evolving Systems Development," International Journal of Information Technology and Management (4:4), 2005, pp. 423-442.

Adams, C., and Avison D. E. "Dangers Inherent in the Use of Techniques: Identifying Framing Influences," Information Technology \& People (16:2), 2003,pp. 203-234.

Adams, J. Conceptual Blockbusting: A Guide to Better Ideas, Harmondsworth, UK: Penguin, 1987.

Bharadwaj, S., and Menon, A "Making Innovation Happen in Organizations: Individual Creativity Mechanisms, Organizational Creativity Mechanisms or Both?," Journal of Product Innovation Management (17:6), 2000, pp. 424-434.

Bicheno, J. The Quality 50: A Guide to Gurus, Tools, Wastes, Techniques and Systems, Buckingham, UK: PICSIE Books, 1994.

Bloomfield, B. P. "Understanding the Social Practice of Systems Developers," Journal of Information Systems (2), 1992, pp. 189-206.

Cascio, W. F. "Virtual Workplaces: Implications for Organizational Behavior," in C. L. Cooper and D. M. Rosseau (eds.), The Virtual Organization, Chichester, UK: Wiley, 1999, pp. 1-14.

Couger, J. D. Creative Problem Solving and Opportunity Finding, Boston: Boyd and Fraser, 1995.

Couger, J. D., Higgins, L., and McLntyre, S. "(Un)Structured Creativity in Information Systems Organizations," MIS Quarterly (17:4), 1993, pp. 375-397.

de Bono, E. Lateral Thinking: A Textbook of Creativity, Harmondsworth, UK: Penguin, 1977. de Bono, E. The Mechanism of Mind, Harmondsworth, UK: Penguin, 1969.

Gabor, D. Innovations: Scientific, Technological and Social, New York: Oxford University Press, 1970.

Gibson, R. Rethinking the Future, London: Nicholas Brealey Publishing, 2003.

Gladstein, D. L. "Groups in Context: A Model of Task Group Effectiveness," Administrative Science Quarterly (29), 1984, pp. 499-517.

Harrison, I. The Book of Inventions: The Stories Behind the Inventors of the Modern World, London: Casselli Illustrated/Octopus Publishing, 2006.

Huchinsonm C., and Rosenberg, D. "The Organization of Organizations: Issues for NextGeneration Office IT," Journal of Information Technology (9:2), 1994, pp. 99-117.

Huebner, J. "The Decline of Innovation," Technological Forecasting and Social Change (72:8), 2005, pp. 980-986.

Jantsch, E. "Technological Forecasting in Perspective," report for the Organization for Economic Co-operation and Development (OECD), Paris, 1967.

Obolensky, N. Practical Business Re-engineering: Tools and Techniques for Achieving Effective Change, London: Kogan Page, 1994.

Roberts, R. M. Serendipity, New York: John Wiley, 1989.

Royal Society. Risk Analysis Perception and Management, London: The Royal Society, 1992.

Stewart, R. "The Use of Social Paradigms in the Analysis of Team Behaviour During Organisational Change," in Proceedings of the United Kingdom Systems Society Conference, New York: Plenum, 1991, pp. 377-382.

Weick, K., and Roberts, K. "Collective Mind in Organizations: Heedful Interrelating on Flight Decks," Administrative Science Quarterly (38), 1993, pp. 357-381.

\section{About the Author}

Carl Adams had over a decade of professional experience in software development before entering academia. His research interests include information systems development (particularly creativity/problem solving activities), current technologies (e/m-commerce), and their impact on people and organizations. His Ph.D. (Southampton University) was in dealing with uncertainty within ISD. Carl can be reached by e-mail at carl.adams@port.ac.uk. 